\title{
Fictionalism about Impossible Worlds
}

\author{
Yusuke SATAKe
}

\begin{abstract}
:
As philosophers have discovered theoretical limits of intensional frameworks for analyzing philosophical phenomena, which have been partly but intimately developed along with the theories about possible worlds, the attention directed to impossible worlds as further theoretical resources has been increasing. This fact naturally provokes the ontological question: what is the nature of impossible worlds? Given the growing importance of the ontology of impossible worlds, I aim to defend the fictionalism about impossible worlds in this paper. First, I divide the positions in the ontology of impossible worlds into six kinds based on whether possible and impossible worlds are concrete, abstract, or fictional. Second, I examine each position and show that the most promising view is that impossible worlds are fictional while possible worlds are either concrete or abstract. Finally, I consider and try to accommodate possible concerns with the fictionalism about impossible worlds.
\end{abstract}

\section{Keywords:}

Impossible worlds, Fictionalism, Possible worlds semantics, Modality, Hyperintensionality

\section{Introduction}

Impossibility accompanies possibility. When someone says, "it's impossible to find the world's best cook outside of China," he means that it is not possible to find the world's best cook outside of China. When someone says, "it's not impossible to find the world's secondbest cook outside of China," she means that it is possible to find the world's second-best cook outside of China. It is our pre-philosophical assumption that possibility and impossibility are 
interdefinable. We cannot make sense of any statement about possibility without making sense of the corresponding expression about impossibility. This parallelism leads us to the question, "is there any difference of meaning among statements about impossibility as different possibility statements?" Or, if not, does the sentence, "it is impossible to simultaneously climb Mt. Everest and Mt. Fuji” have the same meaning as the sentence, "Claude Lévi-Strauss cannot be a pair of jeans?"

Likewise, philosophers, many of whom take possibility seriously as a part of their theories, have been focusing increasing attention on impossibility. Besides, many such philosophers regard impossible worlds as a good potential tool to deal with impossibility. The motivation stems from their philosophical practice with modal concepts. Since the advent of possible worlds semantics, different modal theories have been proposed in various philosophical fields. For example, the fundamental idea of the semantics that the extension of each expression is relativized to possible worlds has been applied to the analysis of counterfactuals. ${ }^{1}$ According to the analysis, the truth of a counterfactual in a world is determined by the truths of relevant sentences in the world(s) closest to the original world. The analysis of counterfactuals, in turn, is applied to some other modal notions such as causation and dispositions. ${ }^{2}$ As another example, the above idea of possible worlds semantics is used to distinguish co-extensional but intensionally different expressions such as "being renate" and "being cordate." 3 The extension of the two expressions is supposedly the same in the actual world, but there might be a possible world in which an entity has a heart but no kidneys. This point, in turn, has been applied to the ontology of property by contemporary nominalists. ${ }^{4}$ Another important application of the concept of possible worlds is that to the contents of beliefs. ${ }^{5}$ Assuming the truths of propositions relativized to worlds, we can analyze the content of a belief as the set of worlds in which the proposition holds. Further examples of modal metaphysics include the analyses of the supervenience relation, essences, and ontological dependence.

As we see the shadow of impossibility behind possibility in ordinary contexts, the above facts in philosophy have urged some contemporary philosophers to get involved with the realm of impossible worlds. ${ }^{6}$ For instance, as described above, the concept of possible worlds

1 Cf. Lewis (1973a) and Stalnaker (1968).

2 For example, see Lewis (1973b) and Lewis (1997), respectively.

3 This example is from Quine (1963: 21).

4 Cf. Rodriguez-Pereyra (2002).

5 Cf. Stalnaker (1984).

6 Nolan (2014), for example, gives many examples of the application of impossible worlds to metaphysics. 
enables us to clarify the meaning of counterfactuals, which are not necessarily vacuously true even if the antecedent is actually false. Appealing to truths in possible worlds, we can clarify and distinguish the meanings of different counterfactuals. However, what if the antecedent of a counterfactual is impossible? How could we find the closest world in which the impossible antecedent holds among all the possible worlds? Further, how could we define the closeness of impossible worlds without postulating them? Given that the traditional analysis of counterfactuals leaves such counterpossibles vacuously true, the cases of such conditionals indicate the requirement for more fine-grained analysis. When it comes to the intensional distinction of expressions, what about the case of necessarily co-extensional expressions such as "being trilateral" and "being a triangle?" It is not possible that their attributions have different truth-values. This might lead us to consider more fine-grained resources that can semantically distinguish intensionally equivalent expressions, and impossible worlds would be one candidate for such resources. Analogously, the examples of modal metaphysics in the previous paragraph would provoke relevant questions about impossible worlds.

Some might think that there is no need to postulate impossible worlds in addition to possible worlds because, as I pointed out at the outset, every statement about impossibility can be paraphrased into the negation of the corresponding statement about possibility. That way, we can give a semantic explanation for all modal expressions including those about impossibility. This apparently suffices to explain the cases mentioned above. However, this approach does not cover all of them. First, in order to grasp the nontrivial sense of counterpossibles, which distinguishes true counterpossibles from false counterpossibles, we have to postulate impossible worlds and define the closeness among them. ${ }^{7}$ As for co-intensional expressions, if we stick to their distinction in terms of the extensions relativized to worlds, we have to postulate impossible worlds. This is because the original problem is that the expressions always have the same extension in each possible world. Appealing to an impossible world in which an object is trilateral but not a triangle, we would manage to distinguish the meanings of "being trilateral" and "being a triangle." These arguments indicate that impossible worlds should have not only a negative characterization as the negation of possibility but also a positive theoretical role in the relevant philosophical theories. As an example, to give the meaning of the sentence, "if the law of non-contradiction were false, I would be neither a Trumpist nor a non-Trumpist," it is not sufficient to assume that there is no possible world in which the utterer is neither a Trumpist

7 Incidentally, Stalnaker (1968) postulates an "absurd world" where every sentence is true to give a meaning to counterpossibles. However, as Lewis (1973a) points out, this postulation is dispensable for Stalnaker. Whether or not it postulates an absurd world, his theory can vacuously assign truth to all counterpossibles. 
nor a non-Trumpist. Rather, we must assume that there is an impossible world in which the utterer is neither a Trumpist nor a non-Trumpist.

Once we accept the legitimacy of a philosophical theory about impossible worlds, we have to undertake their ontology at the same time. This point is analogously derived from David Lewis's following argument for the existence of possible worlds.

I believe that there are possible worlds other than the one we happen to inhabit. If an argument is wanted, it is this. It is uncontroversially true that things might be otherwise than they are. I believe, and so do you, that things could have been different in countless ways. But what does this mean? Ordinary language permits the paraphrase: there are many ways things could have been besides the way they actually are. On the face of it, this sentence is an existential quantification. It says that there exist many entities of a certain description, to wit 'ways things could have been'. I believe that things could have been different in countless ways; I believe permissible paraphrases of what I believe; taking the paraphrase at its face value, I therefore believe in the existence of entities that might be called 'ways things could have been'. I prefer to call them 'possible worlds'. (Lewis, 1973a, 84)

Lewis states that our ordinary discourse on modal expressions has the ontological commitment to possible worlds. ${ }^{8}$ The same argument applies to possible worlds semantics. According to possible worlds semantics, modal sentences are paraphrased into sentences that quantify over possible worlds. Therefore, if we accept the truth of some modal sentences and possible worlds semantics, we are ontologically committed to possible worlds. Likewise, if our philosophical theory about counterfactuals, properties, or beliefs involves the quantification over impossible worlds, we are committed to the existence of impossible worlds.

Given the ontological problem of impossible worlds, I will advocate the fictionalism about impossible worlds in this paper. In section 2, I will list the possible positions about the ontology of impossible worlds. From sections 3 to 5, I will examine each position. In particular, in section 5, I will introduce the fictionalism about impossible worlds and compare it with the other views. In section 6, I will consider possible concerns about the fictionalism about impossible worlds and how the view can accommodate them.

8 Here, I assume that Lewis follows Quine's criterion of existence, "To be is to be the value of a variable" (Quine, 1963, 15). 


\section{A Picture of the Debate}

The debate on the ontology of impossible worlds can be understood analogously to the debate on the ontology of possible worlds. Thus, let us look at how we can categorize the positions about the ontology of possible worlds. The most prominent point of differentiation that has attracted plenty of arguments in this debate is whether possible worlds are concrete or not. Those who advocate the concreteness of possible worlds are called "concretists." "They think that possible worlds have spatiotemporal location as our actual world does. The advocates of this view include Lewis (1986), Rodriguez-Pereyra (2002), and Yagisawa (2010). On the other hand, those who regard possible worlds as abstract are called "abstractionists." A typical strategy of them is to analyze the concept of possible worlds in terms of actual or abstract entities such as propositions, states of affairs, and properties. ${ }^{10}$ For example, Adams (1974) analyzes a possible world as the maximal consistent set of propositions that hold in the world. Though most advocates of possible worlds fall into either concretism or abstractionism, there is another kind of view called "fictionalism." According to this view, the whole story of possible worlds is merely a useful fiction, and, being unreal, the quantification over the worlds within the fiction has no ontological commitment. The advocates of modal fictionalism include Armstrong (2004) and Rosen (1990). Rosen states that, by taking the truths about possible worlds as truths in fiction, we can fully take advantage of the theoretical benefits of possible worlds theories without paying any ontological cost.

The debate on the ontological nature of impossible worlds can be put in an analogous way. That is, we can categorize the positions in terms of whether they are concrete, abstract, or fictional. However, the position about possible worlds may restrict the position about impossible worlds as we shall see below. Therefore, the positions about impossible worlds should be defined jointly with those about possible worlds.

First, if we take the fictionalism about possible worlds, the only plausible position about impossible worlds is fictionalism because it seems absurd that impossible worlds are nonfictional while possible worlds are fictional. I will call this view "extended fictionalism." Second, if we adopt abstractionism about possible worlds, we might take either abstractionism or fictionalism about impossible worlds. Arguably, concretism would be precluded, given the widespread motivation of abstractionism about possible worlds that concrete possible worlds are too counterintuitive to accept. That is, when one finds concrete possible worlds too

9 Here, I follow van Inwagen (1986) in terminology.

10 For example, see Adams (1974), Armstrong (1989), Plantinga (1974), Rescher (1979), and Stalnaker (1976). 
counterintuitive, it would be even more counterintuitive to accept concrete impossible worlds. I will call the abstractionists about possible worlds with the abstractionism about impossible worlds "extended abstractionists" and those with the fictionalism about impossible worlds "abstractionist fictionalists." Finally, the concretism about possible worlds seems open to three kinds: extended concretism, concretist abstractionism, and concretist fictionalism. ${ }^{11}$ To see the debate more schematically, the following table might help.

\begin{tabular}{lcccc}
\hline & \multicolumn{2}{c}{ Possible worlds } & \multicolumn{2}{c}{ Impossible worlds } \\
\cline { 2 - 5 } & Fictional? & Abstract? & Fictional? & Abstract? \\
\hline $\begin{array}{l}\text { Extended } \\
\text { fictionalism }\end{array}$ & Yes & & Yes & \\
$\begin{array}{l}\text { Abstractionist } \\
\text { fictionalism }\end{array}$ & No & Yes & Yes & \\
$\begin{array}{l}\text { Extended } \\
\text { abstractionism }\end{array}$ & No & Yes & No & Yes \\
$\begin{array}{l}\text { Concretist } \\
\text { fictionalism }\end{array}$ & No & No & Yes & \\
$\begin{array}{l}\text { Concretist } \\
\text { abstractionism }\end{array}$ & No & No & No & Yes \\
$\begin{array}{l}\text { Extended } \\
\text { concretism }\end{array}$ & No & No & No & No \\
\hline
\end{tabular}

Assuming the above categorization, let us examine each position.

\section{Extended Concretism and Extended Abstractionism}

\subsection{Ordinary discourse}

Though there might be several problems in extended concretism and abstractionism, the most pressing problem, I think, is that they are involved with both the ontological commitment to impossible worlds and the negation of it, leading to a contradiction. ${ }^{12}$ This concern stems from the intuition that accepting the existence of something impossible is ridiculous. The

11 Yagisawa $(1988 ; 2010)$ is an extended concretist, though the view is called "extended modal realism" in his terminology. Concretist abstractionism is suggested by Berto (2009) under the name of "hybrid modal realism."

12 For example, as other objections to extended views, Berto (2009) points out the following problems. First, if extended concretism is correct, we might have to accept the primitive concepts of modality, which spoils one merit of concretism about possible worlds to reduce modality to possible worlds. This point is, in fact, another way to put the problem I will describe here. Further, if extended concretism is correct, we are forced to accept that impossible propositions hold in the actual world. 
intuition might be observed in our ordinary discourse about impossibility. Let us look at examples.

"I believe that it is impossible to find the world's best cook outside of China. Therefore, I believe that there is a way we could not find the world's best cook outside of China." "I cannot live without her. Therefore, I think there is an impossible way to live without her."

"There is no possible way to square a circle. Therefore, there is an impossible way to square a circle."

The awkwardness of the above examples indicates that, at least in ordinary language, the impossibility of a situation implies that the situation does not exist. At this point, the ontological problem of impossible worlds differs from that of possible worlds. That is, as Lewis pointed out in the previous quote, our ordinary language allows for the paraphrase from a modal sentence into an existential sentence about a way the world might have been. However, our linguistic intuition says that the analogous paraphrase is not acceptable in the case of impossibility. Simply put, ordinary discourse is in favor of realism about possible worlds but ill-disposed to realism about impossible worlds.

\subsection{Semantic clarification}

A semantic consideration would help to grasp the tension between our talks about impossibility and the postulation of the ways things could not have been. For example, consider the counterpossible, "if human beings had no reason, then they would be nothing but reeds." Some advocates of impossible worlds might accept the following truth-condition for the sentence. ${ }^{13}$

"If human beings had no reason, then they would be nothing but reeds" is true in world $\mathrm{w}$ iff, for some $\mathrm{x}, \mathrm{x}$ is the closest world to $\mathrm{w}$ in which human beings have no reason, and they are nothing but reeds in $\mathrm{x}$.

On the other hand, if extended abstractionism is correct, we take over the problem of abstractionism about possible worlds that we cannot avoid the primitive notion of modality.

13 The following truth-condition is intended to be simple for the brevity of the following argument. As an example of more formal treatment, see Nolan (1997). 
Obviously, the right-hand side of the above formula is committed to the existence of the impossible world in which human beings have no reason. Therefore, if we accept the truth of the above sentence and the truth-condition for it, we are committed to the existence of the impossible world.

On the other hand, as I mentioned in section 1, impossibility is definable as the negation of possibility. Accordingly, the advocate of the above truth-condition for the counterpossible would also accept the following truth-condition for the impossibility.

"It is impossible that human beings have no reason" is true in w iff there is no world accessible from $w$ in which human beings have no reason.

The right-hand side of the formula is the negation of the ontological commitment to the world in which human beings have no reason.

The above observation clarifies why regarding something impossible as existent is ridiculous. In an ordinary context, we roughly assume the following statements. First, quantifying over an object without any disclaimer such as "I heard that" or "A contradiction implies that" commits us to its existence. Second, impossibility is understood as the negation of possibility. These two assumptions jointly lead to the absurdity of accepting the existence of impossible entities. That is, regarding something as impossible is equal to regarding the thing as not possible. This, in turn, leads to the negation of the ontological commitment to the entities, which is incompatible with their existence. ${ }^{14}$

The same argument goes for a theory that involves the quantification over impossible worlds as well as possible worlds. That is, once a philosopher accepts an extended sort of semantics that covers impossible worlds as well as possible worlds, he is likely to give a semantic account of impossibility statements in terms of the negation of possibility statements. Then, if he quantifies over any impossible world to give the meaning of an expression, he is committed to a contradiction because the proposition that grounds the impossibility of the world is originally understood as the negation of possibility, which implies the negation of the

14 Strictly speaking, my argument here mixes possible and impossible worlds semantics, which is controversial. I cannot discuss the relation between the two semantics in this paper, to which it would be worth devoting a whole paper. However, I believe that my arguments below maintain substantive consequences without settling the problem and contribute to clarifying how we should understand the relation between the two semantics. I am grateful to the anonymous reviewer for reminding me of this point. 
ontological commitment to the world. I will call the problem that the negation of possibility spoils the existence of impossible worlds the "NPSIP problem." 15

\subsection{Extended views and the NPSIP problem}

The NPSIP problem straightforwardly refutes extended concretism. According to the view, all worlds including impossible worlds are concrete as is the actual world. No world is ontologically privileged, and all worlds are equally in the domain of the realistic quantifier. Let us look at the consequence of this view. Suppose that a theory of extended concretism includes the sentence, "It is impossible that frogs are reptiles," and it postulates an impossible world in which frogs are reptiles. If the theorist accepts possible worlds semantics, he will accept the following truth-condition of the sentence.

The sentence, "It is impossible that frogs are reptiles," is true in world w iff there is no accessible world from $\mathrm{w}$ in which frogs are reptiles.

Because extended concretists are concretists about all worlds, the "world" in the above truthcondition is interpreted as an object that is spatiotemporally located. Therefore, by accepting the truth of the sentence and possible worlds semantics, the extended concretist implies that there is no concrete world in which frogs are reptiles. On the other hand, it is supposed that the extended concretist postulates the concrete impossible world in which frogs are reptiles, leading to the NPSIP problem. Therefore, because the above argument holds for all pairs of impossible propositions and the relevant impossible worlds, extended concretists cannot consistently accept the existence of impossible worlds in general. Further, we can make the

15 Interestingly, Lewis (1986, 7, fn. 3) points out a problem that is similar to but different from the NPSIP problem. According to Lewis, accepting a world in which a contradiction holds implies the truth of a contradiction in the actual world. For example, that $\mathrm{P}$ and $\neg \mathrm{P}$ hold in an impossible world implies both that $\mathrm{P}$ holds in the impossible world and that it is not the case that $\mathrm{P}$ holds in the impossible world. Although this problem is different from the NPSIP problem that postulating impossible worlds may contradict our ordinary understanding of impossibility as the negation of possibility, they are similar to each other in that both of them show that postulating impossible worlds can lead to a contradiction. More interestingly, Vacek (2013) indicates possible solutions to Lewis's problem that may be applicable to the NPSIP problem. Although I cannot examine how the two problems are analogously treated and Vacek's solutions work, it is worth noting that Vacek's solutions require us either to accept that paraconsistent logic correctly represents reality or to deny that contradiction in a world implies a contradiction in the actual world. I am grateful to the anonymous reviewer for reminding me of the similarity between the two problems. 
analogous argument against extended abstractionism by appropriately replacing what the term "possible/impossible worlds" means.

The problem of extended concretism and abstractionism consists in the fact that they include both possible and impossible worlds in one and the same domain of their realistic quantifier. They have no ontological resource to distinguish impossible worlds from possible worlds. This fact commits them to both the existence of impossible worlds and its negation.

\section{Concretist Abstractionism}

Concretist abstractionism seems to avoid the NPSIP problem. This view ontologically distinguishes impossible worlds from possible worlds. Therefore, the negation of the commitment to a possible world does not conflict with the existence of the relevant impossible world. Let us look at an example. According to Berto (2009), impossible worlds might be understood as inconsistent sets of atomic propositions while possible worlds are taken as concrete. ${ }^{16}$ An atomic proposition is, in turn, understood as the set of possible worlds in which the proposition holds. That way, we can represent impossible worlds without postulating any new kind of entity.

For example, suppose that $\mathrm{A}$ and $\mathrm{B}$ are atomic propositions and cannot be true at the same time. In this case, if a world permits both A and B to be true, then the world is an impossible world. According to Berto's view, the impossible world is analyzed by concrete possible worlds. First, A and B are defined as the sets of concrete possible worlds in which A and B hold, respectively. Second, the impossible world in which both A and B are true is defined as the set of propositions that includes A and B as members. Because each proposition is a set of possible worlds, the ontological nature of impossible worlds is explained in terms only of concrete possible worlds and a set-theoretic framework.

According to this view, impossible worlds as sets of propositions are ontologically distinguished from possible worlds that are concrete. Given this, defining impossibility as the negation of possibility does not conflict with the postulation of impossible worlds. That is, stating that there is no concrete world in which both A and B are true is compatible with the statement that there is an abstract world in which both $\mathrm{A}$ and $\mathrm{B}$ are true.

However, this approach cannot discriminate two impossible, atomic propositions. ${ }^{17}$ As introduced above, according to Berto, impossible worlds are inconsistent sets of propositions.

16 Berto himself says that his concretist abstractionism is "just the sketch of a theory" (Berto, 2009, 486) and leaves it an open question whether the view is tenable or not.

17 Berto $(2009,484-5)$ notes this problem but does not give a solution. 
Therefore, a world in which an impossible, atomic proposition holds is an impossible world because, if a set of propositions includes an impossible proposition, then there is no interpretation that has all the members of the set true at the same time. Further, according to Berto's view, propositions are sets of possible worlds in which the propositions hold. Therefore, an impossible proposition would be represented as an empty set. After all, the worlds that are impossible only because impossible atomic propositions hold are all represented as sets of sets of possible worlds that include an empty set as a member. However, if so, the view cannot distinguish two worlds that differ only in having different impossible, atomic propositions. For example, suppose that the propositions that person $\mathrm{S}$ is Pelé's favorite soccer ball and that $\mathrm{S}$ is the statue of Kim Jong-il are both metaphysically impossible. If Berto's view is correct, both propositions are represented as an empty set. That is, his view lacks hyperintensional distinction among impossible propositions in the cases of impossible atomic propositions.

In addition, this problem has a further undesirable consequence for the advocates of impossible worlds in analyzing counterpossibles. Consider the above two impossible propositions again. It is plausible that the closest impossible world in which $\mathrm{S}$ is Pelé's favorite soccer ball is the world with the minimum difference from the actual world due to the absence of S. The same goes for the second proposition. That is, the two impossible worlds are different only in whether S is Pelé's favorite soccer ball or the statue of Kim Jong-il. However, both propositions are an empty set and indiscernible according to Berto's view. Therefore, because an impossible world is understood as the set of propositions that hold in the world, the closest world in which S is Pelé's favorite soccer ball is identical to the closest world in which $\mathrm{S}$ is the statue of Kim Jong-il. Nevertheless, if S were Pelé's favorite soccer ball, many people would kick him while, if he were the statue of Kim Jong-il, no one would kick him.

Although there might be other options for concretist abstractionists to represent impossible worlds, the above point seems to cause trouble in every kind of concretist abstractionism. The general problem is as follows. First of all, the general strategy of the view is to give the ontological ground of impossible worlds in terms of already-acknowledged entities such as concrete or abstract possible existents. The advocates of the view would try to carry this out by appealing to a unifying theory of the acknowledged entities such as set theory or a combinatorial framework. However, this view, in principle, cannot give a fine-grained distinction among those impossible worlds that cannot be constructed out of the acknowledged entities, for such impossible worlds are only negatively definable in one way. For example, in the case of Berto's view, impossible atomic propositions cannot be constructed out of possible worlds, and all of them are only definable appealing to an empty set, which dissolves the distinction among 
them. This, in turn, dissolves the distinction among the impossible worlds that differ from each other in terms only of impossible, atomic propositions.

The fact that concretist abstractionism lacks the distinction among some impossible propositions and impossible worlds undercuts a motivation of the view. According to Berto (2009), his concretist abstractionism is proposed as a solution to reconcile the dilemma between the shortcomings of extended concretism and extended abstractionism partly in response to Graham Priest's following passage.

As far as I can see, any of the main theories concerning the nature of possible worlds can be applied equally to impossible worlds: they are existent non-actual entities; they are non-existent objects; they are constructions out of properties and other universals; they are just certain sets of sentences.... There is, as far as I can see, absolutely no cogent (in particular, non-question-begging) reason to suppose that there is an ontological difference between merely possible and impossible worlds. (Priest, 1997, 580-1)

That is, Berto's view is supposed to manage the problems of the extended views including that extended abstractionism cannot distinguish impossible propositions without circularity while extended concretism is committed to absurd consequences. By showing that his view can accommodate the problems, Berto tries to give a sufficient reason to violate Priest's parity thesis between possible and impossible worlds. However, given that Berto's concretist abstractionism lacks the distinction among impossible atomic propositions, it cannot give a cogent reason to posit an ontological difference between possible and impossible worlds.

\section{Fictionalism about Impossible Worlds}

\subsection{Articulating the fictionalism about impossible worlds}

So far, I have shown that, if we take the truth of a theory about impossible worlds seriously and try to give a realistic account of impossibility, then we are led to a dilemma. If we take either of extended concretism or abstractionism, then we confront the NPSIP problem, resulting in a contradiction. On the other hand, if we adopt concretist abstractionism, we fall short of ontological resources, being unable to distinguish impossible atomic propositions. These observations motivate us to think that, when we are talking about impossible worlds, we are just playing with a false story. That is, though we might appeal to impossible worlds to give a semantic analysis for counterpossibles, to distinguish impossible propositions, properties, and 
belief contents, all the theories we adopt in these contexts are not true just because we negate the ontological commitment to impossible worlds.

The fictionalism about impossible worlds I advocate is introduced as follows. First, we can establish a semantic theory that quantifies over impossible worlds on demand. For example, we might adopt a theory that gives truth-conditions for counterpossibles in terms of the world in which a conditional is evaluated and the comparable closeness relation to the original world among impossible worlds, which quantifies over impossible worlds. Then, we relativize the truth of truth-conditions to fiction. Recall the truth-condition of the counterpossible in section 3.2 .

"If human beings had no reason, then they would be nothing but reeds" is true in world $\mathrm{w}$ iff, for some $\mathrm{x}, \mathrm{x}$ is the closest world to $\mathrm{w}$ in which human beings have no reason, and they are nothing but reeds in $\mathrm{x}$.

In order to become a fictionalist about impossible worlds, all we need to do is to add the disclaimer, "according to the semantics of counterpossibles."

"If human beings had no reason, then they would be nothing but reeds" is true in world $\mathrm{w}$ iff, according to the semantics of counterpossibles, for some $\mathrm{x}, \mathrm{x}$ is the closest world to $\mathrm{w}$ in which human beings have no reason, and they are nothing but reeds in $\mathrm{x}$.

That way, we can fully take advantage of our talks about impossible worlds. The only difference from realist theory is that all our talks about impossible worlds are false in reality according to the fictionalism. The truths are defined relative to the fictionalist theory. However, we will never be committed to the existence of impossible worlds because we do not adopt the theory to describe reality. It is merely useful.

The fictionalism about impossible worlds does not suffer from the problems of the other views described in the preceding sections. First, the view accommodates the NPSIP problem. Whether we take concretism or abstractionism about possible worlds, the quantification over impossible worlds does not conflict with the negation of the ontological commitment to impossible worlds. This is simply because all our talks about impossible worlds are false and have no ontological commitment to them. Second, we will not suffer from the problem of impossible atomic propositions anymore. Given that the fictionalism about impossible worlds is not involved with the NPSIP problem, there is no need for a fictionalist to appeal to a particular fiction that assumes an abstract understanding of impossible worlds. Once we accept 
the fiction of non-representational impossible worlds, we are free from the concern in the limited resources of representation. Finally, dissolving the problems that accompany the other realistic views, the fictionalism about impossible worlds would find a cogent reason to violate the parity thesis.

\subsection{Prioritizing the three kinds of fictionalism}

However, which of extended fictionalism, concretist fictionalism, or abstractionist fictionalism we should take is still controversial. In this section, I will show that we should take either concretist or abstractionist fictionalism for the following reasons. First, the fictionalism about possible worlds has no sufficient motivation. Second, whether we should take the concretism or abstractionism about possible worlds is determined independently of the fictionalism about impossible worlds.

For the first point, let us look at Rosen's (1990) argument for the fictionalism about possible worlds. For those who take the ontological commitment to possible worlds seriously, there are two options in deciding their metaphysical position behind the theories of possible worlds. One is abstractionism and the other is concretism. ${ }^{18}$ The former is ontologically more modest than the latter because it does not postulate possible objects in addition to actual existents, representing possible objects and worlds in terms of actually existing abstract entities. However, abstractionism has a theoretical limit due to the limit of the ontological resources to represent possible worlds. Therefore, it eventually does not deliver the expected explanatory role for a modal theory, such as reducing modality and offering a fine-grained framework to discern all possible existents. ${ }^{19}$ On the other hand, the concretism about possible worlds gives a better account of modal phenomena than the abstractionism because the view has nothing to do with technical problems of representation. However, concretists suffer from the "incredulous stare" at the existence of uncountable concrete possible worlds, which are too counterintuitive to accept. ${ }^{20}$ Abstractionism is insufficient, but concretism is too bizarre. To reconcile the tension between the concretism and the abstractionism about possible worlds, Rosen suggests that we take the concretistic account of possible objects and just regard it as false. In this way, we can give a thoroughgoing theory on modality while avoiding counterintuitive consequences in ontology. While Lewis states that the ontological cost of concretism is worth taking, Rosen states that the cost is unnecessary.

18 Rosen himself calls the two positions "ersatz modal realism" and "modal realism," respectively.

19 For precise objections to the abstractionism about possible worlds, see Lewis (1986: Ch. 3)

20 Cf. Lewis (1986: 133-5). 
I do not think that Rosen's reasoning justifies the fictionalism about possible worlds. According to Rosen, Lewis's concretism about possible worlds answers all the stated objections except for the problem of the incredulous stare. ${ }^{21}$ That is, Rosen tries to motivate the fictionalism about possible worlds only to avoid the incredulous stare. However, the substantive content of the incredulous stare is the intuition that it drastically conflicts with our common sense that there exist countless concrete possible worlds. Although intuition often gives us a strong motivation to doubt a philosophical theory, it cannot give a decisive reason to deny the theory. Or, at most, intuition only negatively works in choosing a philosophical theory among other candidates when there is no other difference in the theoretical virtues of the theories in question. That is, intuition itself should be neutral on which philosophical theory is correct while it might say something about which is preferred. Likewise, our incredulous stare at countless possible worlds is originally neutral on whether they exist. However, Rosen's fictionalism says more, positively denying their existence. Therefore, Rosen's above reasoning does not justify us to neglect realism about possible worlds and adopt the fictionalism about them.

On the other hand, if we take Rosen's reasoning seriously, all ontological debates might turn into a matter of intuition. The general structure of his reasoning is as follows. First, there are several theories about a philosophical topic. Second, one of them is the most theoretically beneficial in terms of, for example, explanatory power, ontological parsimony, and so on. However, the theory is committed to an intuitively unpalatable ontology. Therefore, we should adopt the theory while regarding it as false, so we can enjoy its benefits without suffering from the ontological bizarreness. This reasoning is one side of a coin. That is, if we accept the above reasoning as a plausible criterion for determining whether we take fictionalism or not, it would become a metaontological principle in the choice of a theory that if the most theoretically beneficial view requires an intuitively acceptable ontology, then take it at face value; otherwise, take it and regard it as false. If the principle holds, every ontological debate would eventually be settled by intuition, which is far from interesting.

Incidentally, the side effect of the above point is that it clarifies why we are justified to adopt the fictionalism about impossible worlds. The problem of Rosen's fictionalism is that it is only sustained by the fact that the best realistic account of possible worlds is intuitively unacceptable, and deriving the plausibility of fictionalism based on this fact makes ontological debates uninteresting. The lesson of this is that we should take fictionalism about an object only if no other views are tenable in the sense that they are consistent and have sufficient explanatory power to cover all the cases to be explained. Given that we have to admit

$21 \quad$ Cf. Rosen (1990: 329). 
fictionalism when there is no other choice, the opposite direction of the above conditional also arguably holds. Therefore, having no choice other than fictionalism just gives the necessary and sufficient condition for adopting fictionalism. The fictionalism about impossible worlds seems to meet the condition. In sections 3 and 4, we examined possible realistic positions about impossible worlds, resulting in a dilemma. The extended views are committed to a contradiction, violating the consistency condition of tenability. On the other hand, concretist abstractionism generally has the cases that cannot be explained due to the limit of representational resources, violating the requirement of sufficient explanatory power. These give a positive reason to adopt the fictionalism about impossible worlds.

Another reason to deny the fictionalism about possible worlds, and thereby the extended fictionalism, is that it seems to indicate that all modal features of the actual world have nothing to do with reality. According to Rosen's fictionalism about possible worlds, we can freely quantify over Lewisian possible worlds without paying attention to the ontological problems of both concretism and abstractionism. Therefore, all the modal expressions are explained by quantifying over the worlds. The only thing we must accept is that the quantification is within the scope of a fictionalistic operator. However, accepting this would undermine the relation of modal truths to reality. For example, suppose that the counterfactual, "if Donald Trump were hit by Mike Pence, he would get angry," is true in the actual world. Rosen's fictionalism would give a Lewisian truth-condition, which quantifies over possible worlds, with a fictionalistic operator for this sentence. Truths in possible worlds are relativized to fiction and regarded as false in reality. Therefore, what the truth-condition of the counterfactual says is true only in fiction and false in the actual world. However, the sentence is obviously about the actual Trump, and the truth of it seems to concern a real feature of the world.

Further, the fictionality of the truth-conditions of counterfactuals would be taken over by some other modal features of the actual world, such as causal relations and dispositions. For example, many philosophers advocate the counterfactual analysis of causal relations. ${ }^{22}$ According to this view, the attribution of the causal relation between two events depends on the truth of the relevant counterfactual. Given that what the truth-condition of a counterfactual says is false in the actual world according to the fictionalism about possible worlds, there is no real ground for the attribution of a causal relation in the actual world. Nevertheless, we are inclined to think that some causal relations hold in virtue of some real feature of the world. The same goes for the ascription of dispositions. Again, the counterfactual analysis of disposition ascription is one of the most prominent views. According to this view, whether an object has a

22 For example, see Lewis (1973b). 
disposition depends on the truth of the relevant counterfactual. However, if the fictionalism about possible worlds is correct, all the ascriptions of dispositions would turn out to be unrelated to reality. Nevertheless, we are strongly urged to think that some dispositions are real features of the actual world. For example, it is highly plausible that a glass is fragile in virtue of an actual property of the glass rather than mere fiction.

On the contrary, we would not think that counterpossibles are features of the actual world. Likewise, it seems implausible that causal relations that have necessary causes, if any, and dispositions with impossible stimulus conditions are features of the actual world. For example, suppose that the counterpossible, "if the earth were a zero-dimensional object, the North Pole would fuse with the South Pole," is true in the actual world. Is there any realistic ground for this sentence in the actual world? Does the sentence describe any actual disposition or causal property of the North Pole? It seems not. Although I cannot find a general argument to exclude all these things from the features of the actual world, I cannot, at the same time, find any reason to think that the sentence is true in virtue of the actual features of the world. Therefore, it seems plausible that regarding all statements about impossible worlds as merely fictional is not harmful. For the above two reasons, I conclude that we should not assume the fictionalism about possible worlds while maintaining the fictionalism about impossible worlds.

On the other hand, the fictionalism about impossible worlds is open to both the concretism and abstractionism about possible worlds. As I said above, once we allow for a fictional form of an ontological theory about impossible worlds, we can bring up any fiction to explain the philosophical phenomenon in question on demand. ${ }^{23}$ The fictional theory might be either concretistic or abstractionistic, but this in no way affects our ontological view about possible worlds. This is simply because our fictional story about impossible worlds is false and has no ontological import, and, thereby, it cannot conflict with our theory about possible worlds in principle. Though there might be a decisive argument that forces us to adopt either the concretism or abstractionism about possible worlds, the argument would be given independently of our fictional theory about impossible worlds. Therefore, while advocating the fictionalism about impossible worlds, I prefer to be on the side of neither concretists nor abstractionists about possible worlds.

To sum up, once we accept a philosophical theory that quantifies over impossible worlds, we must address the question about the ontological nature of impossible worlds. If we seek a realistic answer to the question, we are involved with a dilemma. For one thing, if we adopt extended abstractionism or concretism, we are forced to admit both the existence and the

23 It is important to stick to the usefulness and on-demandness of the theory. This point would be supported from the perspective of ideological parsimony. I will get back to this point in section 6.3. 
absence of impossible worlds. On the other hand, if we adopt concretist abstractionism, we cannot give the desired distinction among impossible worlds because of the limited resources of representation. Neither of the realistic views gives a satisfactory theory of impossible worlds. These facts give us a reason to adopt the fictionalism about impossible worlds, which avoids all the problems in the realistic positions that I introduced. However, which fictionalism we should take is still an open question. Regarding this, at least, extended fictionalism has two problems. First, the motivation of the view consists only of our intuition, which does not give a sufficient reason to prioritize fictionalism about possible worlds over realism. Second, the fictionalism about possible worlds makes all the modal truths in the actual world ungrounded. Therefore, assuming that the fictionalism about impossible worlds says nothing about the debate on which of the concretism and abstractionism about possible worlds is more plausible, I conclude that either concretist fictionalism or abstractionist fictionalism is the most plausible option among the ontological theories about impossible worlds.

\section{Concerns}

\subsection{Meinongianism?}

Throughout the discussion in this paper, I have assumed that the quantification over an object implies the ontological commitment to the object. This implies that accepting the truth of expressions quantifying over impossible worlds commits us to their existence. For example, I argued that extended concretism and abstractionism amount to a contradiction because they, jointly with worlds semantics, acknowledge and negate the ontological commitment to impossible worlds. The ground of my argument was that both views quantify over impossible worlds and have no ontological distinction between possible and impossible worlds. To derive the above conclusion from the ground, we must assume that the quantification over an object always accompanies the ontological commitment to it. In discussing concretist abstractionism, I pointed out that the view does not involve a contradiction because it ontologically distinguishes possible worlds from impossible worlds even if it includes both possible and impossible worlds in the same domain. The point was that, although the view involves both the ontological commitment to impossible worlds and the negation of the ontological commitment to the corresponding possible worlds, the former is compatible with the latter, thanks to the ontological distinction between the two kinds of worlds. In introducing the fictionalism about impossible worlds, I tried to escape from the ontological commitment to impossible worlds by stating that 
all the talks about impossible worlds are false. That way, we can avoid the ontological commitment to impossible worlds even if the fictional theory quantifies over them.

The above facts indicate that we might find a further option in the ontology of impossible worlds by getting rid of the assumption that the quantification over an object implies the ontological commitment to the object. By doing this, we can allow both existing and nonexisting objects to belong to one and the same domain of the realistic quantifier. This kind of view might give another solution to the NPSIP problem. That is, an advocate of the view might state that the quantification over impossible worlds does not imply the ontological commitment to them.

One way to spell out this idea is to introduce the predicate "existing" and state that not the domain of the theory but the predication of existence determines what exists. For example, our theory might quantify over impossible worlds as well as possible worlds. However, according to this view, this does not imply that we accept the existence of impossible worlds as well as possible worlds because whether or not impossible worlds exist is determined by whether or not they belong to the extension of the predicate "existing." Therefore, unless an object simultaneously belongs to the extension of "existing" and its complement in the domain of the theory, we are not committed to a contradiction. I will call this view "Meinongianism about impossible worlds." Although I will not go into details about this view in this paper, I will give some brief comments on the view, which seems in favor of the fictionalism about impossible worlds.

First, it is unclear how Meinongianism about impossible worlds is significantly different from the fictionalism about impossible worlds from an ontological perspective. Though each view can have variety in what kind of worlds they regard as impossible or possible, once we assume that the two views agree on a particular distinction between possible and impossible worlds, their ontology seems to have no difference. That is, given that they coincide in what is possible and what is not, they would accept the same collection of worlds as existent or nonexistent, whether the concept of existence consists in quantification or predication. It might be stated that, even if they agree on the collections of existing and non-existing worlds, they differ in which worlds are (more) real or fundamental and which are not. This point might provoke interesting ontological questions, but they are outside the scope of this paper. ${ }^{24}$ Instead of

24 For example, the above point is related to the following questions. First, is being real or fundamental different from existing? If so, second, can a world be real or fundamental? If so, third, which worlds are real or fundamental? Recently, many philosophers have been prominently discussing reality and fundamentality, and it is hard to raise all their examples. That said, as influential examples, see Fine (2001), Schaffer (2009), and Sider (2011). 
discussing them, I tentatively conclude that Meinongianism and the fictionalism about impossible worlds do not differ in what exists.

Even if the two views agree on what exists, they might have different semantic import. According to Meinongianism about impossible worlds, both possible and impossible worlds are equally quantified within one and the same domain and distinguished in terms of the predication of existence. This suggests that all statements about possible and impossible worlds are dealt with in a language based on the same logical space. However, as Yagisawa (1988) pointed out, some impossibility statements are about a different logical space from ours, and giving substantive meanings to such impossibility statements is one of the benefits of welcoming impossible worlds. For example, according to Yagisawa, to analyze the sentence, "there could be more worlds than there actually are in our logical space," we must appeal to an alternative logical space. It seems that Meinongianism cannot straightforwardly analyze Yagisawa's example.

On the other hand, the fictionalism about impossible worlds has no trouble in dealing with the example. It is plausible that, according to fictionalism, when we talk about impossible worlds, we use a different language from the language we use in talking about reality. We are based on different kinds of quantifiers with different domains. According to fictionalism, our talk about impossible worlds is, in its nature, that about an alternative logical space. Given this, fictionalism would not have trouble in dealing with Yagisawa's example.

Indeed, I am not convinced that the above points decisively prioritize fictionalism over Meinongianism. However, given that the two views are arguably on a par with each other from an ontological perspective and that fictionalism is more convenient in dealing with Yagisawa's example than Meinongianism, I prefer the former to the latter from a practical perspective.

\subsection{Is there a substantive difference between fictionalism and abstractionism?}

One might state that there is no substantive difference between fictionalism and abstractionism about impossible worlds. Although abstractionists accept the existence of impossible worlds, their strategy is to reduce them to entities that have already been accepted within the framework of possible worlds. That is, if abstractionism is successful, impossible worlds should be nothing over and above possible entities. If so, fictionalism might not be substantively different from abstractionism.

However, there are clear differences. First, abstractionism includes both possible and impossible worlds in the same domain that consists of real entities while fictionalism appeals to additional quantifiers and domains that have no ontological commitment in talking about 
impossible worlds. One of the consequences of this difference is that impossible worlds do not exist according to fictionalism while they do according to abstractionism. Fictionalists contend that the abstractionistic representation is not an impossible world, but, in fact, they say more. Impossible worlds are not only non-representational but also fictional. That is, the difference in the interpretation of the expressions about impossible worlds between the two views is not merely verbal.

Further, they differ in the status of the truth-values of the statements about impossible worlds. The abstractionism is realism, and the truth in its theory is literally true. On the other hand, the truth of fictionalism is true only relative to fiction. Therefore, the truth in a theory of abstractionism is unique, objective, and has realistic ground, but the truth in a fictionalist theory can vary fiction by fiction, is relative to a particular fiction, and has no realistic ground. In fact, fictionalists can accept opposite truths such as propositions $\mathrm{P}$ and $\neg \mathrm{P}$ by appealing to different fictions. So long as the two fictions are useful enough and the truths of $\mathrm{P}$ and $\neg \mathrm{P}$ are relativized to each fiction, fictionalists can accept both truths at the same time. For the reasons above, I conclude that the fictionalism and abstractionism about impossible worlds are substantively different from each other.

\subsection{How can we choose an appropriate fiction?}

As I mentioned in section 5.2, the fictionalism about impossible worlds can appeal to any fiction on demand to analyze the philosophical phenomenon at stake. However, we must take this on-demandness seriously in adopting a particular fiction. In other words, we should not postulate a particular fiction beyond necessity. That is, fictionalism is free from ontological parsimony but not from ideological parsimony.

Then, how is a fictional theory evaluated in terms of on-demandness and ideological parsimony? It is plausible to appeal to the usefulness of the theory. In appealing to a fictional theory to analyze a philosophical phenomenon, whether it conforms to reality is not important. Rather, what matters should only be how useful it is in the analysis. Therefore, a plausible principle to figure out the appropriate fiction about a philosophical problem is that we should maximize the usefulness while minimizing the ideological resources in solving the problem.

Now, the natural question to ask next is what the usefulness of a theory is. Although I cannot fully characterize the general concept of usefulness of a theory here, at least, its basic understanding is clear enough and shared by the other ontological positions about impossible worlds. I assume that the basic idea of usefulness is that, when a theory is useful for solving a philosophical problem, it includes the sentences that suffice for solving the problem. For 
example, if sentences $S$ and $S^{\prime}$ jointly solve the problem on their own, then a consistent set of sentences that contain both $\mathrm{S}$ and $\mathrm{S}$ ' would be a useful theory for solving the problem. In the case of fictionalism, the theory would be considered a useful fiction. This standard of usefulness, together with the criterion of parsimony, would work for determining the appropriate theory to solve a philosophical problem. That is, the appropriate fiction must not require any ideological resources beyond necessity while guaranteeing to solve the problem, as the other views must require neither ontological nor ideological resources beyond necessity while guaranteeing to solve the problem. Though the above observation about the usefulness of a theory is not thoroughgoing, I believe that it has shown that the concept is not that mysterious and that, if defining the concept brings about any difficulty to fictionalism, the other views would also face the same difficulty.

Instead of further clarifying the general concept of usefulness, I will briefly describe a general strategy to achieve the best fiction among candidate theories in ontology. Suppose that the ontological nature of a certain kind of object, $\mathrm{O}$, is considered. If we are justified in adopting the fictionalism about $\mathrm{O}$, we should take the following two steps. First, we establish a realistic theory about $\mathrm{O}$ that maximizes the explanatory power (or any other elements that contribute to the usefulness in this context) while minimizing the explanatory instruments that eventually affect the ideological economy of the final fiction. Second, we regard the whole theory as false.

\subsection{In what sense is fiction philosophically important?}

According to the fictionalism about impossible worlds, every theory quantifying over impossible worlds is false and has no ontological commitment to them. Every truth in such a theory is true only in fiction. These facts indicate that fictional theories have nothing to do with reality and, conversely, there is no realistic ground for them. Then, it is natural to ask, "in what sense is a fiction philosophically important?" As the ending remark of this paper, I will articulate my opinion on this question.

Recall the examples of our ordinary discourse about impossible situations in section 3.1. Our intuition suggests that we are hesitant to accept the existence of impossible situations given the understanding of impossibility as the negation of possibility. On the other hand, our ordinary discourse seems to give enough evidence for the fact that we make sense of the distinction among impossible propositions and situations. For example, the sentence, "if Hobbes had squared a circle, the surrounding people would have been amazed," seems true, but the sentence, "if Hobbes had squared a circle, he would have been taller than actual," seems false. The example indicates that we sensibly evaluate the truth-value of sentences 
about impossible situations. That is, we seem to maintain the reasoning about impossible situations even if we deny their existence.

Fictionalism accommodates these facts. As our ordinary discourse assumes, fictionalism denies the existence of the ways things could not have been. We sometimes might talk about impossible situations, but the fictionalism about impossible worlds does not force us to accept their existence in explaining the meaning of our talk. However, this does not mean that fictionalism says nothing about our ordinary discourse about impossibility. It can clarify how we distinguish impossible propositions and situations by appealing to a useful fiction. Given that our intuition is not inclined to regard impossibility as a part of reality, there seems to be no problem of the real distinction among impossible propositions and situations. What we need is a way to distinguish them without assuming what the distinction is. For this, it is enough to give a model-theoretic framework to accommodate our reasoning about impossibility, which can be provided by the fictionalism about impossible worlds as a useful fiction.

To see the above point more clearly, let us think formally. Our purpose is to show why a fictional theory about impossible worlds can discern different sentences about impossibility without requiring the existence of impossible worlds. For this, it suffices to show that the distinction holds only relative to the theory. Taking an example, let $\mathrm{S}_{1}$ and $\mathrm{S}_{2}$ be different counterpossibles with different truth-conditions $T_{1}$ and $T_{2}$ according to the semantics of counterpossibles. Also, suppose that $\Gamma_{\mathrm{R}}$ is the set of all the true sentences. Assuming the truthcondition of counterpossibles we have seen in section $3.2, \mathrm{~T}_{1}$ and $\mathrm{T}_{2}$ quantify over impossible worlds. Thus, according to fictionalism, $\mathrm{T}_{1}$ and $\mathrm{T}_{2}$ are false in reality. Nevertheless, we may think that $\mathrm{S}_{1} \in \Gamma_{\mathrm{R}}$ and $\mathrm{S}_{2} \notin \Gamma_{\mathrm{R}}$. That is, we can semantically distinguish different counterpossibles. A particular fiction and the concept of truth relativized to fiction can explain this fact. Let $\Gamma_{F}$ be the set of the true sentences in the fictionalist theory including $\mathrm{T}_{1}$ but not $\mathrm{T}_{2}$, and $\mathrm{M}_{\mathrm{F}}$ a model that makes all the members of $\Gamma_{F}$ true but not $T_{2}$. The relevant fact, in this case, is that $M_{F}$ makes $\mathrm{T}_{1}$ true but $\mathrm{T}_{2}$ false. Here, indeed, the domain of $\mathrm{M}_{\mathrm{F}}$ must contain the relevant impossible worlds, but this does not mean that we are ontologically committed to them. None of the facts above require the fact that the domain of a model of $\Gamma_{R}$, which is different from $M_{F}$, contains an impossible world. On the other hand, the above facts can explain why we can semantically distinguish $\mathrm{S}_{1}$ from $\mathrm{S}_{2}$ because there is no harm in regarding the sentences, "the worlds semantics of counterpossibles is correct" and " $T_{1}$ is a member of $\Gamma_{F}$, but $T_{2}$ is not" (or " $T_{1}$ is true while $\mathrm{T}_{2}$ is false according to the semantics of counterpossibles"), as literally true.

It is a part of the claims of fictionalism that the truth of sentences about impossible worlds is not grounded by reality. However, this point is irrelevant to whether we can semantically distinguish two different sentences about impossibility. To explain this fact, we need the 
quantification over impossible worlds, but we do not need their existence according to the fictionalism. It is an important question whether expressions about impossible worlds have absolute truth-values, but saying, "No," to the question does not imply that the fictionalism is philosophical nonsense.

\section{Acknowledgments}

I am sincerely grateful to Kevin Gausselin, Paul Audi, Shimpei Endo, Vincent Tanzil, and Zeynep Soysal for productive discussions and many critical, helpful comments on the draft of this paper.

\section{References}

Adams, R. M. (1974). Theories of Actuality. Noûs, 8, 211-231.

Armstrong, D. M. (1989). A Combinatorial Theory of Possibility. Cambridge University Press.

Armstrong, D. M. (2004). Truth and Truthmakers. Cambridge University Press.

Berto, F. (2009). Impossible Worlds and Propositions: Against the Parity Thesis. Philosophical Quarterly, 60, 471-486.

Fine, K. (2001). The Question of Realism. Philosophers'Imprint, 1, 1-30.

Lewis, D. K. (1973a). Counterfactuals. Blackwell.

Lewis, D. K. (1973b). Causation. Journal of Philosophy, 70, 556-567.

Lewis, D. K. (1986). On the Plurality of Worlds. Wiley-Blackwell.

Lewis, D. K. (1997). Finkish Dispositions. Philosophical Quarterly, 47, 143-158.

Loux, M. J. (ed.) (1979). The Possible and the Actual: Readings in the Metaphysics of Modality. Cornell University Press.

Manley, D., Chalmers, D. \& Wasserman, R. (Eds.) (2009). Metametaphysics: New Essays on the Foundations of Ontology. Oxford University Press.

Nolan, D. (1997). Impossible Worlds: A Modest Approach. Notre Dame Journal of Formal Logic, 38, 535-572.

Nolan, D. (2014). Hyperintensional Metaphysics. Philosophical Studies, 171, 141-160.

Plantinga, A. (1974). The Nature of Necessity, Clarendon Press.

Priest, G. (1997). Sylvan's Box. Notre Dame Journal of Formal Logic, 38, 573-581.

Quine, W. V. O. (1963). From a Logical Point of View, Harper Torchbook edition, Harper \& Row.

Rescher, N. (Ed.) (1968). Studies in Logical Theory (American Philosophical Quarterly Monographs 2). Blackwell. 
Rescher, N. (1979). The Ontology of the Possible. in M. J. Loux (Ed.) (1979), 166-181.

Rodriguez-Pereyra, G. (2002). Resemblance Nominalism: A Solution to the Problem of Universals, Oxford University Press.

Rosen, G. (1990). Modal Fictionalism. Mind, 99, 327-354.

Schaffer, J. (2009). On What Grounds What. in D. Manley, D. Chalmers \& R. Wasserman (Eds.) (2009), $347-383$.

Sider, T. (2011). Writing the Book of the World. Oxford University Press.

Stalnaker, R. (1968). A Theory of Conditionals. in N. Rescher (Ed.) (1968), 98-112.

Stalnaker, R. (1976). Possible Worlds. Nô̂s, 10, 65-75.

Stalnaker, R. (1984). Inquiry. The MIT Press.

Vacek, M. (2013). Concrete Impossibile Worlds. Filozofia, 68, 523-529.

van Inwagen, P. (1986). Two Concepts of Possible Worlds. Midwest Studies in Philosophy, 11, 185-213.

Yagisawa, T. (1988). Beyond Possible Worlds. Philosophical Studies, 53, 175-204.

Yagisawa, T. (2010). Worlds and Individuals, Possible and Otherwise. Oxford University Press.

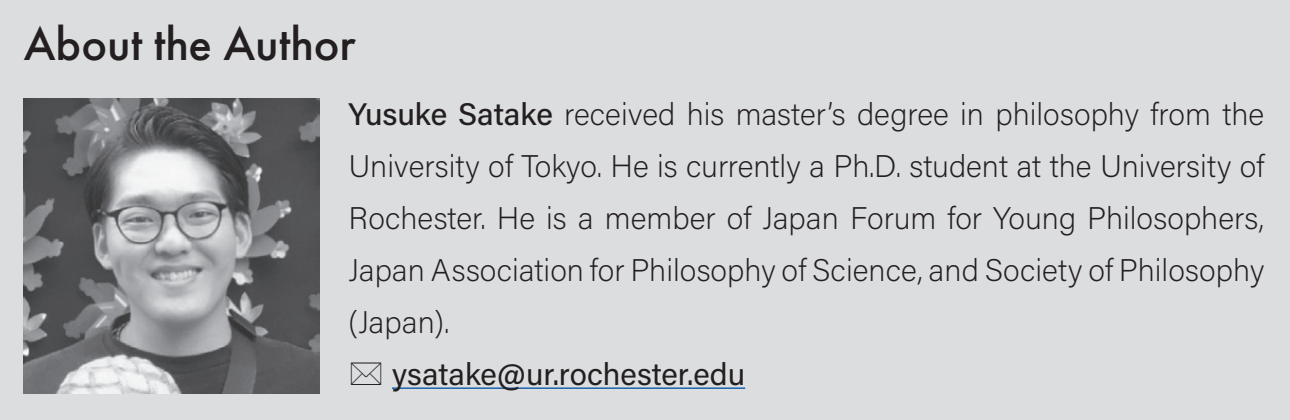


